\title{
Effect of deposition conditions and thermal annealing on the charge trapping properties of $\mathrm{SiN}_{x}$ films
}

\author{
Yongling Ren, ${ }^{\text {a) }}$ Klaus J. Weber, Natalita M. Nursam, and Da Wang \\ Centre for Sustainable Energy Systems, College of Engineering and Computer Science, The Australian \\ National University, Canberra, Australian Capital Territory 0200, Australia
}

(Received 19 August 2010; accepted 28 October 2010; published online 18 November 2010)

\begin{abstract}
The density of charge trapping centers in $\mathrm{SiN}_{x}: \mathrm{H}$ films deposited by plasma enhanced chemical vapor deposition is investigated as a function of film stoichiometry and postdeposition annealing treatments. In the as-deposited films, the defect density is observed to increase with an increasing $\mathrm{N} / \mathrm{Si}$ ratio $x$ in the range of $0.89-1.45$, and to correlate with the $\mathrm{N}-\mathrm{H}$ bond density. Following the annealing in the temperature range of $500-800{ }^{\circ} \mathrm{C}$, the defect density increases for all N/Si ratios, with the largest increase observed in the most $\mathrm{Si}$ rich samples. However, the defect density always remains highest in the most $\mathrm{N}$ rich films. The better charge storage ability suggests the $\mathrm{N}$ rich films are more suitable for the creation of negatively charged nitride films on solar cells. (C) 2010 American Institute of Physics. [doi:10.1063/1.3518488]
\end{abstract}

Hydrogenated, amorphous silicon nitride $\left(\alpha-\mathrm{SiN}_{x}: \mathrm{H}\right)$ films have been widely used in semiconductor devices such as thin film transistors, memory devices, and solar cells. Charge plays an important role in many of these applications, and in some cases, the ability to manipulate charge is critical. In silicon solar cells, the positive charge in the as-deposited films is often beneficial as it results in field effect passivation of $\mathrm{n}$ type surfaces. However, for p-type surfaces, the positive charge in $\mathrm{SiN}_{x}$ induces a depletion region that increases recombination, and results in a parasitic shunt that reduces cell short circuit currents. ${ }^{1}$ Therefore, the ability to trap negative charge in $\mathrm{SiN}_{x}$ for long periods of time could be of interest for solar cell applications, and indeed, an improved passivation resulting from negatively charged $\mathrm{SiN}_{x}$ films has already been demonstrated. ${ }^{2}$

The K-center defect, which consists of an $\mathrm{Si}$ atom backbonded to three nitrogen atoms $\left(\mathrm{Si} \equiv \mathrm{N}_{3}\right)$ is the amphoteric defect chiefly responsible for trapped charge in near stoichiometric $\mathrm{SiN}_{x}$ films. ${ }^{3}$ The ability of $\mathrm{SiN}_{x}$ films to trap the negative charge is mainly determined by the K-center density, which shows a strong dependence on film deposition conditions and postdeposition treatments. Several authors have explored the effect of deposition conditions and postdeposition thermal treatments on the film properties including the K-center density. ${ }^{4-8}$ In these reports, the charge storage ability is indirectly measured through measurement of the neutral K-center density using electron spin resonance (ESR). Such measurements require great care to ensure that (i) all of the $\mathrm{K}$ centers are neutral at the time of ESR measurement (which requires UV treatment) and that (ii) the $\mathrm{K}$ centers are not photobleached..$^{9}$ In this paper, we present a study on the effect of deposition parameters and thermal annealing on the charge trapping properties of $\mathrm{SiN}_{x}$ films. As an alternative to ESR measurements, we measure the density of charge directly trapping centers from capacitance-voltage $(C-V)$ measurements following the injection of negative charge.

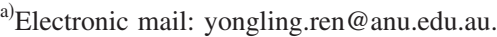

P-type, (100), double sided polished Si wafers were used as the substrates for Fourier transform infrared (FTIR) spectroscopy and Rutherford backscattering spectrometry (RBS) measurements. Substrates used for $C$ - $V$ measurements were $\mathrm{Cz}$, p-type, and 1-10 $\Omega \mathrm{cm}$ (100) Si wafers. After a standard RCA clean, $90 \mathrm{~nm} \mathrm{SiN}_{x}$ was deposited on all samples using a plasma enhanced chemical vapor deposition (Oxford PlasmaLab 80) at a frequency of $13.56 \mathrm{MHz}$, a temperature of $400{ }^{\circ} \mathrm{C}$, pressure of 1 Torr, and rf power of $24.7 \mathrm{~W}$. For the samples used for $C-V$ measurements, a $20 \mathrm{~nm}$ tunnel oxide layer was thermally grown at $900{ }^{\circ} \mathrm{C}$ before the deposition of the $\mathrm{SiN}_{x}$ films, which serves as a barrier to charge decay, and thus improves the stability of the charge in the $\mathrm{SiN}_{x}$ film. ${ }^{10,11}$ Various $\left(\mathrm{SiH}_{4}+5 \% \mathrm{~N}_{2}\right): \mathrm{NH}_{3}$ gas ratios $\left(R_{\text {gas }}\right)$ were used in the deposition of $\mathrm{SiN}_{x}$ films, namely, $R_{\text {gas }}$ $=3.7,6.5,20,27$, and 34 for samples A, B, C, D, and E, respectively. The total gas flow rate was kept constant at 420 (SCCM) (SCCM denotes standard cubic centimeters per minute at STP). After deposition, selected $C$ - $V$ and FTIR samples were rapid thermal annealed at various temperatures in the range of $500-800{ }^{\circ} \mathrm{C}$ for $30 \mathrm{~s}$.

The refractive index $n$ and film thickness were measured using a multiple angle reflectometer (FilmTek 4000) at a wavelength of $633 \mathrm{~nm}$ and an incidence angle of around $70^{\circ}$. The N/Si ratio $x$ was estimated from $n$ using the empirical expression $^{5,6}$

$$
x=\frac{[\mathrm{N}]}{[\mathrm{Si}]}=\frac{4\left(n_{\alpha-\mathrm{Si}: \mathrm{H}}-n\right)}{3\left(n+n_{\alpha-\mathrm{Si}: \mathrm{H}}-2 n_{\alpha-\mathrm{Si}_{3} \mathrm{~N}_{4}}\right)}=\frac{4(3.3-n)}{3(n-0.5)},
$$

where $n_{\alpha-\mathrm{Si}: \mathrm{H}}=3.3$ and $n_{\alpha-\mathrm{Si} 3 \mathrm{~N} 4}=1.9$ are the refractive index of amorphous silicon $(a-\mathrm{Si}: \mathrm{H})$ and nearly stoichiometric silicon nitride $\left(a-\mathrm{Si}_{3} \mathrm{~N}_{4}\right)$, respectively. For comparison, RBS measurements were also performed on selected as-deposited samples to determine their N/Si ratios. It was found that the $\mathrm{N} / \mathrm{Si}$ ratios determined from RBS are in good agreement with the values calculated from Eq. (1) for $\mathrm{N}$ rich, $\mathrm{Si}$ rich and nearly stoichiometric films.

Information on chemical bond densities in as deposited and annealed $\mathrm{SiN}_{x}$ films was obtained from FTIR spectroscopy, using the general expression ${ }^{12}$ 


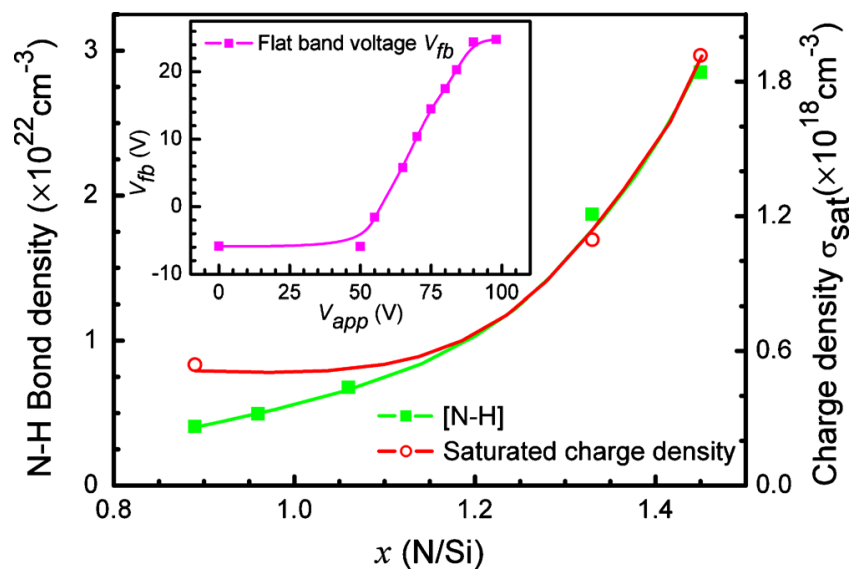

FIG. 1. (Color online) Saturated charge density $\sigma_{\text {sat }}$ and the calculated N-H bond density as a function of N/Si ratio for the as-deposited films. The inset shows a typical plot of flatband voltage $V_{\mathrm{fb}}$ vs applied bias voltage $V_{\text {app }}$. Lines are guides to the eyes.

$$
[A-B]=C_{A-B} \int \alpha(\omega) \omega^{-1} d \omega,
$$

where $\alpha(\omega)$ and $\omega$ are the absorption coefficient and the wave number, respectively, and $C_{A-B}$ is the proportionality constant, where the proportionality constants of Bustarret et $a .^{5}$ were used.

For $C$ - $V$ measurements, $\mathrm{Al}$ dots with an area of $\sim 0.0048 \mathrm{~cm}^{2}$ were evaporated on the front and $\mathrm{In} / \mathrm{Ga}$ contacts were formed on the rear of the samples. To inject electrons into $\mathrm{SiN}_{x}$ film, progressively increased positive bias voltages $V_{\text {app }}$ were applied to the front metal contacts for periods of several seconds. Following each bias voltage, a high frequency $C-V$ sweep was carried out to determine the flatband voltage $V_{\mathrm{fb}}$. $V_{\text {app }}$ was increased until saturation of $V_{\mathrm{fb}}$ was observed. With the following two assumptions: (i) the saturated charge (with all the K centers fully charged) are roughly uniformly distributed throughout the film, ${ }^{13,14}$ and then the charge centroid will be located in the middle of the film; (ii) the positive charge density of films prior to charge injection can be associated with interface defects carrying a fixed positive charge, ${ }^{15}$ while the sum of charge due to $\mathrm{K}$ centers is assumed to be zero initially (Since the neutral state of the $\mathrm{K}$ center is believed to be metastable, ${ }^{16}$ the silicon nitride film is likely to consist of roughly equal densities of positively and negatively charged $\mathrm{K}$ centers), the saturated flatband voltage $V_{\mathrm{fb}}$ following charge injection can then be used to estimate the K-center density (density of fundamental charges per unit area) in the $\mathrm{SiN}_{x}$ films

$$
\sigma=-\frac{2 C_{i}}{q A_{A l}}\left(V_{\mathrm{fb}}-V_{0}\right)
$$

where $V_{0}$ is the flatband voltage of the film prior to charge injection, $C_{i}$ is the capacitance of the nitride, $q$ is the elementary charge, and $A_{A l}$ is the $\mathrm{Al}$ electrode area.

Figure 1 shows the variation of the saturated charge density $\sigma_{\text {sat }}$ and the $\mathrm{N}-\mathrm{H}$ bond density with $\mathrm{N} / \mathrm{Si}$ ratio for the as-deposited films. The inset of Fig. 1 shows a typical plot of flatband voltage $V_{\mathrm{fb}}$ as a function of applied bias voltage $V_{\text {app }}$. An increase in $\sigma_{\text {sat }}$ with increasing $\mathrm{N}$ content in the film is observed, which accords with the electron spin resonance measurements reported. ${ }^{17,18}$ As reported, ${ }^{17,18}$ the ESR spin density increases with increasing the N/Si ratio for the $\mathrm{Si}$ -

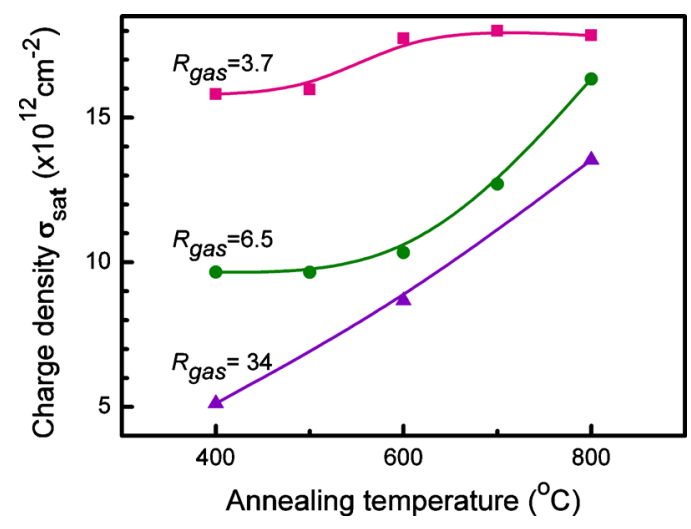

FIG. 2. (Color online) Saturated negative charge density $\sigma_{\text {sat }}$ as a function of annealing temperature for sample A, B, and E. Lines are guides to the eyes. Note: $400{ }^{\circ} \mathrm{C}$ is the deposition temperature.

rich and nearly stoichiometric regions. However, the ESR spin density drops with further increasing the N/Si ratio over a percolation threshold ( $x=1.3$ and 1.1 for the films in Refs. 17 and 18 , respectively). For our samples, the $\sigma_{\text {sat }}$ increases all the way with increasing the N/Si ratio from 0.89 to 1.45 with no percolation threshold observed, the reasons of which are not very clear and remain to be studied further. Furthermore, it can be seen that there exists a reasonably close correlation between the $\sigma_{\mathrm{sat}}$ and $[\mathrm{N}-\mathrm{H}]$, which was also observed by Garcia et al. ${ }^{18}$ (It should be mentioned that $[\mathrm{N}]$ does not present such close correlation with $\sigma_{\text {sat }}$ despite the fact that it also increases with increasing the $\mathrm{N} / \mathrm{Si}$ ratio.) Mäckel and Lüdemann ${ }^{4}$ proposed a model, whereby the formation of $\mathrm{K}$ centers during film deposition proceeds when a $\mathrm{H}$ atom is lost from an $\mathrm{H}-\mathrm{SiN}_{3}$ precursor in the presence $\mathrm{H}-\mathrm{NSi}_{2}$, with the latter catalyzing the reaction. The results of Fig. 1 support the idea that $\mathrm{N}-\mathrm{H}$ bonds play an important role in the creation of $\mathrm{K}$ centers.

Following deposition, selected N-rich (sample A), stoichiometric (sample B), and Si-rich (sample E) films were annealed at $500,600,700$, and $800{ }^{\circ} \mathrm{C}$. Figure 2 shows $\sigma_{\text {sat }}$ as a function of annealing temperature. $\sigma_{\text {sat }}$ increases with increasing annealing temperature for all three samples, with the largest increase observed for the Si rich film and smallest for the $\mathrm{N}$ rich film. This increase of $\sigma_{\text {sat }}$ with increasing the annealing temperature also accords with the ESR measurements reported. ${ }^{19}$ As observed in Ref. 19, the spin density decreases after annealing in the temperature range of $300-600{ }^{\circ} \mathrm{C}$. However, it increases after annealing at higher temperature $\left(>600{ }^{\circ} \mathrm{C}\right)$ with the largest increase observed for the Si-rich film. The decrease of spin density after annealing in the lower temperature range was attributed to the charge transfer between two $\mathrm{K}$ centers, leading to the formation of non-ESR active $\mathrm{K}$ centers (not annihilation of $\mathrm{K}$ centers). The increase of spin density after annealing at higher temperatures was explained with the release of hydrogen and the resultant formation of new $\mathrm{K}$ centers. These models proposed agree with our observations that no evidence of a reduction in the density of chargeable defects is observed for sample $\mathrm{A}, \mathrm{B}$, and $\mathrm{E}$ after annealing at higher temperatures $\left(500-800{ }^{\circ} \mathrm{C}\right)$.

Figure 3 shows the density of $\mathrm{N}-\mathrm{H}$ and $\mathrm{H}-\mathrm{SiN}_{3}$ bonds ( $\mathrm{Si}-\mathrm{H}$ bonds backbonded to three $\mathrm{N}$ atoms) for the films annealed at various temperatures. The latter was obtained by fitting the $\mathrm{Si}-\mathrm{H}$ absorption peak with the characteristic peaks 


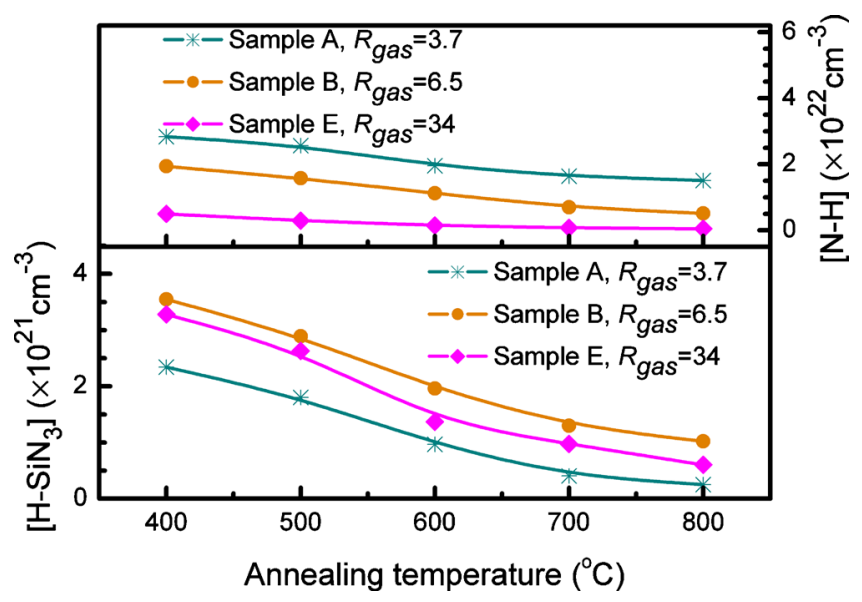

FIG. 3. (Color online) The change of $[\mathrm{N}-\mathrm{H}]$ and $\left[\mathrm{H}-\mathrm{SiN}_{3}\right]$ as a function of annealing temperature for samples A, B, and E. Lines are guides to the eyes. Note: $400{ }^{\circ} \mathrm{C}$ is the deposition temperature.

of the six possible backbonding configurations. ${ }^{5}$ Possible mechanisms for the increase in $\sigma_{\text {sat }}$ during annealing (at temperatures significantly above the deposition temperature) include the $\mathrm{H}-\mathrm{NSi}_{2}$ catalyzed breaking of $\mathrm{H}-\mathrm{SiN}_{3}$ proposed by Mäckel $^{4}$ or the direct dissociation of hydrogen from $\mathrm{H}-\mathrm{SiN}_{3} .{ }^{20,21}$ In the former case, the rate of formation of $\mathrm{K}$ centers would be expected to depend on the product of the $\mathrm{H}-\mathrm{SiN}_{3}$ and $\mathrm{N}-\mathrm{H}$ densities, but in the latter case, it should depend on the density decrease of $\mathrm{H}-\mathrm{SiN}_{3}$. Analysis of the data in Fig. 3 shows that the former correlation does not exist. While Fig. 3 shows that $\mathrm{H}-\mathrm{SiN}_{3}$ bond density decreases at a comparable rate in all the films. So, in principle, a comparable increase of $\sigma_{\text {sat }}$ should be induced. However, as shown in Fig. 2, the $\sigma_{\text {sat }}$ shows quite different increase for three samples, which cannot be purely explained by the breaking of $\mathrm{Si}-\mathrm{H}$ bonds after annealing.

To explain the larger increase of $\sigma_{\text {sat }}$ for samples B and $\mathrm{E}$, other formation mechanism for the $\mathrm{K}$ centers during annealing need to be considered. It was reported that thermal annealing can break weak $\mathrm{Si}-\mathrm{Si}$ bonds in films and generate new Si dangling bonds, resulting in the formation of new $\mathrm{K}$ centers. ${ }^{22,23}$ In stoichiometric and Si-rich films (sample B and $\mathrm{E}$ ), there is a greater density of $\mathrm{Si}-\mathrm{Si}$ bonds than in $\mathrm{N}$-rich films (sample A). The greater increase in $\sigma_{\text {sat }}$ for the films of samples B and E may therefore be the result of a greater density of weak $\mathrm{Si}-\mathrm{Si}$ bonds being broken and converted into $\mathrm{K}$ centers. Optical measurements show that the $\mathrm{N} / \mathrm{Si}$ ratio of samples A and B are virtually unchanged after annealing, while for sample $\mathrm{E}$, the N/Si ratio gradually decreases from 0.85 to 0.68 for annealing temperatures between 500 and $800{ }^{\circ} \mathrm{C}$, indicating a significant loss of $\mathrm{N}$ for $\mathrm{Si}$ rich films after annealing. This is thought to result from the reaction of $\mathrm{Si}-\mathrm{H}$ and $\mathrm{N}-\mathrm{H}$ bonds ${ }^{19}$

$$
\mathrm{Si}-\mathrm{H}+\mathrm{H}-\mathrm{NSi}-\mathrm{H} \Rightarrow \mathrm{Si}-\mathrm{Si}+\mathrm{NH}_{3} \text {. }
$$

This indicates that in $\mathrm{Si}$ rich films, weaker $\mathrm{Si}-\mathrm{Si}$ bonds are created during annealing. As a result, more $\mathrm{K}$ centers can be formed in Si rich films during the annealing process than in $\mathrm{N}$ rich and stoichiometric films.
In summary, we suggest that different mechanisms may be chiefly responsible for the different density of $\mathrm{K}$ centers in as-deposited films, and the increase in their density following annealing. This results in a relatively high density of chargeable defect centers in films with a wide range of stoichiometries following a high temperature annealing. However, $\sigma_{\text {sat }}$ of the $\mathrm{N}$ rich films is always larger than that of the stoichiometric or Si rich films. Together with the larger optical bandgap, which is likely to result in a deeper energy level of the $\mathrm{K}$ center below the conduction band and therefore greater charge stability, this suggests that $\mathrm{N}$ rich films are most suited for application to solar cells, where a large value of $\sigma_{\text {sat }}$ is important to ensure effective surface passivation. ${ }^{24}$

The authors gratefully acknowledge the help of Dr. J. WongLeung with RBS measurements, Dr. W. Lei and Dr. L. Fu with FTIR measurements, Dr. F. Karouta with access to ANFF facilites and Dr. S. Madden, Mr. K. Vu and Dr. R. Wang with Filmtek measurements. Financial support from the Australian Research Council (LP0883613) is gratefully acknowledged.

${ }^{1}$ S. Dauwe, L. Mittelstädt, A. Metz, and R. Hezel, Prog. Photovoltaics 10, 271 (2002).

${ }^{2}$ K. J. Weber and H. Jin, Appl. Phys. Lett. 94, 063509 (2009).

${ }^{3}$ W. L. Warren, J. Kanicki, F. C. Rong, E. H. Poindexter, and P. J. McWhorter, Appl. Phys. Lett. 61, 216 (1992).

${ }^{4}$ H. Mäckel and R. Lüdemann, J. Appl. Phys. 92, 2602 (2002).

${ }^{5}$ E. Bustarret, M. Bensouda, M. C. Habrard, J. C. Bruyère, S. Poulin, and S. C. Gujrathi, Phys. Rev. B 38, 8171 (1988).

${ }^{6}$ D. N. Wright, E. S. Marstein, and A. Holt, 22nd European Photovoltaic Solar Energy Conference, Milan, Italy, 2007, pp. 1651-1655.

${ }^{7}$ A. Zerga, M. Carrada, M. Amann, and A. Slaoui, Physica E (Amsterdam) 38, 21 (2007)

${ }^{8}$ T. H. Kim, J. S. Sim, J. D. Lee, H. C. Shin, and B.-G. Park, Appl. Phys. Lett. 85, 660 (2004).

${ }^{9}$ M. S. Crowder, E. D. Tober, and J. Kanicki, Appl. Phys. Lett. 57, 1995 (1990).

${ }^{10}$ Y. Yang and M. H. White, Solid-State Electron. 44, 949 (2000).

${ }^{11}$ M. H. White, Y. Yang, P. Ansha, and M. L. French, IEEE Trans. Compon., Packag. Manuf. Technol., Part A 20, 190 (1997).

${ }^{12}$ A. Morimoto, S. Oozora, M. Kumeda, and T. Shimizu, Phys. Status Solidi B 119, 715 (1983).

${ }^{13}$ D. T. Krick, P. M. Lenahan, and J. Kanicki, J. Appl. Phys. 64, 3558 (1988).

${ }^{14}$ D. T. Krick, P. M. Lenahan, and J. Kanicki, Phys. Rev. B 38, 8226 (1988).

${ }^{15}$ S. De Wolf, G. Agostinelli, G. Beaucarne, and P. Vitanov, J. Appl. Phys. 97, 063303-1 (2005).

${ }^{16}$ Y. Nakayama, P. Stradins, and H. Fritzsche, J. Non-Cryst. Solids 164-166, 1061 (1993).

${ }^{17}$ T. Makino and M. Maeda, Jpn. J. Appl. Phys., Part 1 25, 1300 (1986).

${ }^{18}$ S. Garcia, D. Bravo, M. Fernandez, I. Martil, and F. J. López, Appl. Phys. Lett. 67, 3263 (1995).

${ }^{19}$ F. L. Martínez, A. del Prado, I. Mártil, D. Bravo, and F. J. López, J. Appl Phys. 88, 2149 (2000).

${ }^{20}$ Y. Deguchi, M. Ohnishi, Y. Takahashi, and K. Ohnishi, Electron. Commun. Jpn., Part 2: Electron. 80, 30 (1997).

${ }^{21}$ J. Kikawa, M. Kaneko, H. Otake, T. Fujishima, K. Chikamatsu, A. Yamaguchi, and Y. Nanishi, Phys. Status Solidi B 247, 1649 (2010).

${ }^{22}$ S. Hasegawa, M. Matsuda, and Y. Kurata, Appl. Phys. Lett. 58, 741 (1991).

${ }^{23}$ M. Stutzmann, Philos. Mag. B 60, 531 (1989).

${ }^{24}$ K. J. Weber, H. Jin, C. Zhang, N. Nursam, W. E. Jellett, and K. R. McIntosh, 24th European Photovoltaic Solar Energy Conference, Hamburg, Germany, 2009, pp. 534-537. 